\title{
POLÍMEROS BIODEGRADÁVEIS - UMA SOLUÇÃO PARCIAL PARA DIMINUIR A QUANTIDADE DOS RESÍDUOS PLÁSTICOS
}

Sandra Mara Martins Franchetti* e José Carlos Marconato

Departamento de Bioquímica e Microbiologia, Universidade Estadual Paulista "Júlio de Mesquita Filho", CP 199, 13506-900 Rio Claro - SP, Brasil

Recebido em 13/12/04; aceito em 21/10/05; publicado na web em 24/3/06

\begin{abstract}
BIODEGRADABLE POLYMERS - A PARTIAL WAY FOR DECREASING THE AMOUNT OF PLASTIC WASTE. The large use of plastics has generated a waste deposit problem. Today plastic wastes represent $20 \%$ in volume of the total waste in the municipal landfills. To solve the disposal problem of plastics methods have been employed such as incineration, recycling, landfill disposal, biodegradation and the use of biodegradable polymers. Incineration of plastic wastes provokes pollution due to the production of poisonous gases. Recycling is important to reduce final costs of plastic materials, but is not enough in face of the amount of discarded plastic. In landfills plastic wastes remain undegraded for a long time, causing space and pollution problems. Biodegradation is a feasible method to treat some plastics, but intensive research is necessary to find conditions for the action of microorganisms. All of these methods are important and the practical application of each one depends on the type and amount of the plastic wastes and the environmental conditions. Therefore, a great deal of research has focused on developing biodegradable plastics and its application because it is an important way for minimizing the effect of the large volume of plastic waste discarded in the world.
\end{abstract}

Keywords: biodegradable polymers; plastic waste; biodegradation.

\section{INTRODUÇÃO}

Até pouco tempo atrás era importante descobrir materiais cada vez mais duráveis para utilização diária no mercado e dentre estes estavam os plásticos, com grande variedade de aplicações, devido a suas propriedades, versatilidade de uso e preço ${ }^{1}$. Como o uso dos plásticos vem aumentando muito no mundo todo (mais de $100 \mathrm{mi}-$ lhões de t/ano de plásticos produzidos) ${ }^{2}$, conseqüentemente é grande a quantidade de resíduos plásticos descartados no meio ambiente, isto é, $20 \%$ do volume total ${ }^{3-5}$. Os plásticos sintéticos, materiais formados de macromoléculas, denominados polímeros (do grego: polimuitos, meros-partes, unidades), são muito resistentes à degradação natural, quando descartados no meio ambiente, isto é, em aterros ou lixões municipais, daí seu acúmulo cada vez mais crescente ${ }^{6,7}$. O consumo de plásticos per capita no mundo é de $19 \mathrm{~kg}^{8}$, sendo que nos EUA é de $80 \mathrm{~kg}$, na Europa $60 \mathrm{~kg}^{9}$ e na Índia $2 \mathrm{~kg}^{9}$. Os plásticos mais utilizados na vida diária, desde 1940, têm sido polietileno (PE), polipropileno (PP), poliestireno (PS), poli(tereftalato de etileno) (PET) e poli(cloreto de vinila) (PVC) que, apesar do avanço no processamento e fabricação, geram dois grandes problemas: o uso de fonte não-renovável (como o petróleo) para obtenção de sua matéria-prima e a grande quantidade de resíduos gerada para descarte ${ }^{10}$. Além disso, é sabido que muitos plásticos exigem mais de 100 anos para degradação total, tendo em vista que sua alta massa molar média e hidrofobicidade dificultam a ação dos microrganismos e de suas enzimas na superfície do polímero ${ }^{11,12}$.

Para tratar de tanto resíduo plástico tem sido empregadas, usualmente, quatro tipos de estratégias:

\section{Incineração}

Este processo apresenta a vantagem de diminuir rapidamente o volume de material descartado, em cerca de $80 \%$. Apesar disto, a

*e-mail: samaramf@rc.unesp.br incineração não é um método recomendável, devido ao alto custo dos fornos de aquecimento e da poluição, produzida pela liberação de produtos tóxicos. No caso do PVC, em particular, quando incinerado lança para a atmosfera $\mathrm{HCl}$ que, acumulado na atmosfera úmida, pode cair como chuva ácida ${ }^{13}$.

\section{Reciclagem}

É um método viável de reaproveitamento de resíduos plásticos, por fusão e transformação destes resíduos em outros materiais utilizáveis comercialmente. Este método apresenta como vantagens a redução da quantidade de resíduos sólidos, a economia de matéria-prima e energia, o aumento da vida útil dos lixões e um alto rendimento do processo ${ }^{14}$. A reciclagem de plásticos envolve um grande trabalho prévio de separação, identificação e limpeza dos recipientes. Ainda assim, o material reciclado é cerca de $50 \%$ mais barato que o polímero virgem. No mundo, cerca de $20 \%$ dos plásticos são reciclado ${ }^{8}$. No Brasil, a reciclagem vem crescendo em volume e aumentando a diversidade e qualidade dos produtos reciclados ${ }^{15}$.

\section{Aterros sanitários}

São usadas para a disposição de toneladas de plásticos em locais afastados da cidade e preparados para acondicionar o grande volume de matéria plástica, que ficará muito tempo exposta ou será utilizada para queima e geração de energia (reciclagem térmica $)^{10}$. Cerca de 14 milhões de t de resíduos plásticos/ano são descartadas em aterros sanitários e mais de 100.000 t/ano são descartadas no mar $^{2}$.

\section{Biodegradação}

É um processo que consiste na modificação física ou química, causada pela ação de microrganismos, sob certas condições de calor, 
umidade, luz, oxigênio e nutrientes orgânicos e minerais adequa$\operatorname{dos}^{10}$. Segundo Flemming ${ }^{16}$, que não utiliza o termo biodegradação e sim, biodeterioração de materiais poliméricos, esta é causada por microrganismos que colonizam sua superfície, formando biofilmes, que consistem de microrganismos embebidos em uma matriz de biopolímeros excretados por eles que, em contato com os polímeros, causam mudanças estruturais e/ou morfológicas. A biodegradação pode ser facilitada por aplicação de processos prévios de luz (UV) e/ou calor na matriz polimérica ${ }^{17}$. A presença de ligações hidrolisáveis ou oxidáveis na cadeia, uma estereoconfiguração correta, um balanço entre hidrofobicidade e hidrofilicidade e uma certa flexilbilidade conformacional são fatores que contribuem para a biodegradação do polímero ${ }^{3}$. Por depender de vários fatores, os testes de biodegradabilidade são de difícil padronização ${ }^{18}$.

Outra maneira de ajudar a diminuir a quantidade de resíduos plásticos persistentes no meio ambiente, pode ser o emprego de polímeros biodegradáveis.

\section{Polímeros biodegradáveis}

Estes polímeros são materiais degradáveis, em que a degradação resulta primariamente da ação de microrganismos, tais como fungos, bactérias e algas de ocorrência natural, gerando $\mathrm{CO}_{2}, \mathrm{CH}_{4}$, componentes celulares e outros produtos, segundo estabelecido pela "American Standard for Testing and Methods" (ASTM-D-833) 11,19. Ou de outro modo, são materiais que se degradam em dióxido de carbono, água e biomassa, como resultado da ação de organimos vivos ou enzimas ${ }^{12}$.

Descobertos há cerca de 10 anos, os plásticos biodegradáveis, também denominados plásticos biológicos ou bioplásticos ${ }^{2}$, hoje ainda têm uma participação mínima no mercado internacional ${ }^{20}$. Apesar da vantagem de sua aplicação quanto à preservação do meio ambiente, os plásticos biológicos são mais caros, e têm aplicações mais limitadas que os sintéticos, por serem menos flexíveis ${ }^{21}$. Em meados da década de 90, iniciou-se no Brasil o desenvolvimento de uma tecnologia para produção de plásticos biodegradáveis empregando como matéria-prima derivados da cana-de-açúcar, a partir de um projeto cooperativo desenvolvido pelo IPT, Copersucar e Universidade de São Paulo. Desta parceria, iniciou-se um estudo, com os polímeros da família dos poli(hidroxialcanoatos) (PHAs), que podem ser produzidos por bactérias em biorreatores a partir de açúcares. Tais polímeros possuem propriedades semelhantes às dos plásticos petroquímicos, com a vantagem de poderem ser biodegradados por microrganismos presentes no meio ambiente, em curto espaço de tempo, após o descarte ${ }^{21}$. O principal representante dos PHAs é o poli( $\beta$-hidroxibutirato) (PHB), semelhante ao polímero sintético, polipropileno (PP), em propriedades físicas e mecânicas ${ }^{21}$.

$\mathrm{O}$ interesse por estes polímeros tem crescido muito nos últimos tempos, no mundo todo. Apesar disto, o alto custo de sua produção ainda é uma grande desvantagem em relação aos polímeros convencionais, basta comparar o custo de produção do PHB estimado a US\$ 2.65/kg para uma planta de 100.000 t/ano, com uso de sacarose como substrato, com o valor do polipropileno US\$ $1.00 / \mathrm{kg}^{22,23}$. Outras estimativas preliminares apresentam um custo de produção de US\$5.85/kg para uma planta de $30.000 \mathrm{t} / \mathrm{ano}^{24,25}$. O custo dos PHAs, utilizando A. eutrophus é de US\$16/kg, isto é 18 vezes mais que o polipropileno ${ }^{2}$. Com $E$. coli o preço pode ser reduzido a US $\$ 4 / \mathrm{kg}$, um custo semelhante a materiais plásticos biodegradáveis, tais como o poli(ácido lático) (PLA) e a poli( $\varepsilon$ caprolactona) (PCL). A produção de PHB demanda $3 \mathrm{~kg}$ de sacarose/ $\mathrm{kg}$ final do produto, sendo que o preço do açúcar representa $29 \%$ do custo final do produto (sem considerar taxas) ${ }^{23}$, portanto, o custo médio de produção do $\mathrm{PHB}$ varia em função do tipo de açúcar empregado, do preço do açúcar, do microrganismo utilizado e da planta de produção ${ }^{23}$.

Os polímeros biodegradáveis podem ser agrupados em duas classes principais ${ }^{21}$ : naturais e sintéticos

\section{POLÍMEROS BIODEGRADÁVEIS NATURAIS}

Polímeros formados durante o ciclo de crescimento de organismos vivos são, então, denominados polímeros naturais. Sua síntese envolve, geralmente, reações catalisadas por enzimas e reações de crescimento de cadeia a partir de monômeros ativados, que são formados dentro das células por processos metabólicos complexos.

\section{Polissacarídeos}

Os principais polissacarídeos de interesse comercial são celulose e amido, havendo uma atenção especial aos carboidratos mais complexos: quitosanas, quitinas e xantanas ${ }^{21}$. Comparandose as estruturas de alguns destes polímeros, verifica-se que são formados por unidades básicas de glicose, ligadas como anéis de grupos acetais (aldeído e álcool) e, portanto, com grande quantidade de grupos hidroxilas (alta hidrofilicidade). A celulose é um polissacarídeo formado de unidades de glicose (Figura 1), presente em madeira, papel e algodão. Os outros polissacarídeos têm estrutura semelhante à da celulose: quitina - é uma molécula complexa encontrada nos crustáceos: caranguejos, siris, lagostas, camarões. Também existe em insetos, fungos, cogumelos e minhocas; quitosana - polímero derivado da quitina, utilizado em aplicações médicas e em programas de perda de peso. Possui significativa compatibilidade com tecidos vivos e melhora a cicatrização de ferimentos; xantana - polímero comercial hifrofílico, muito utilizado como espessante e estabilizante, em cosméticos e alimentos e como cápsulas de liberação controlada de drogas ${ }^{26,27}$.

Estes polímeros naturais são degradados na natureza por fungos, que podem secretar enzimas, que catalisam reações de oxidação da celulose e do amido. As bactérias podem secretar endo e exoenzimas para degradar este tipo de macromolécula. Além disso uma mistura de fungos e bactérias pode agir cooperativamente, isto é, microrganismos específicos degradam celulose a glicose que, por sua vez, chega aos produtos finais da degradação $\mathrm{CO}_{2}$ e água ${ }^{21}$. Outro polissacarídeo, o amido, tem sido utilizado disperso em uma matriz polimérica não-biodegradável, usualmente polietileno (PE), para facilitar a acessibilidade dos microrganismos ao polímero sintético ${ }^{21,28}$. O amido é adicionado como aditivo, sendo degradado facilmente por microrganismos, provocando a degradação parcial da matriz ${ }^{28}$. Amido de batata adicionado a filmes de polietileno de baixa densidade (PEBD) melhorou a biodegradabilidade destes filmes $^{29}$. A adição de amido a resinas de isocianatos reduziu o custo de produção e melhorou sua resistência à solventes ${ }^{21}$. A adição de amido a poli(vinilálcool) levou à perda de massa do polímero e alterações morfológicas na parte amorfa do mesmo ${ }^{30}$.

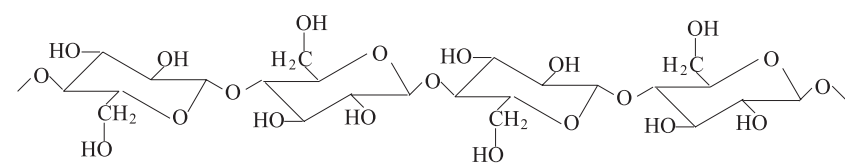

Figura 1. Estrutura da celulose

\section{Ácidos algínicos}

Estes ácidos são formados de monômeros de ácidos manurônico e gulurônico. São solúveis em água e tornam-se insolúveis na pre- 
sença de cátions, como cálcio, berílio, alumínio e ferro, formando géis, que podem servir para liberação controlada de drogas em sistemas vivos, para encapsulamento de herbicidas, microrganismos e células ${ }^{21}$. Estes ácidos estão representados na Figura 2.

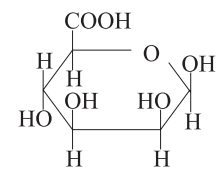

(a)

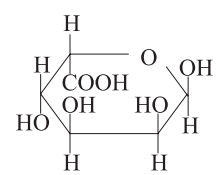

(b)
Figura 2. Estrutura química de ácidos algínicos: a) ácido manurônico, b) ácido gulurônico

\section{Polipetídeos naturais}

As gelatinas são polímeros biodegradáveis, consistindo de proteínas do tipo animal, com grande aplicação industrial, farmacêutica e biomédica, empregados como coberturas e microencapsulação de drogas e no preparo de hidrogéis ${ }^{21}$. Na conformação $\beta$ das proteínas, a cadeia polipeptídica estende-se em uma estrutura em ziguezaque, denominada de folha $\beta^{31}$, mantida por ligações de hidrogênio, como ilustrado na Figura 3.

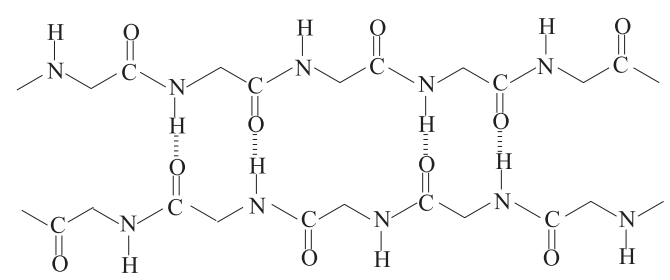

Figura 3. Conformação $\beta$ das cadeias polipeptídicas

\section{Poliésteres bacterianos}

Poliésteres naturais, que são produzidos por uma grande variedade de bactérias, como materiais de reserva intracelular, têm sido alvo de muita atenção para aplicações comerciais, como polímeros biodegradáveis, vantajosamente produzidos por fontes renováveis. Esta classe de polímeros, os poli(hidroxialcanoatos)(PHAs), poliésteres alifáticos, também denominados biopolímeros ou bioplásticos, mostra uma grande variação em suas propriedades, isto é, de materiais rígidos e quebradiços a plásticos com boas propriedades de impacto ou até elastômeros resistentes, dependendo do tamanho dos grupos alquilas ramificados e da composição do polímero ${ }^{2,21}$. Os poli(hidroxialcanoatos) mais conhecidos são poli( $\beta$-hidroxibutirato) (PHB), poli( $\beta$-hidroxivalerato)(PHV) e poli(hidroxibutirato-co-valerato)(PHB-V), sendo este último conhecido comercialmente como Biopol. Suas estruturas químicas podem ser vistas na Figura 4.

Estes poliésteres têm sido sintetizados por vários tipos de microrganismos, tais como Alcaligenes eutrophus ${ }^{32}$, Ralstonia eutropha ${ }^{33}$, Alcaligenes lótus, Comamonas acidvorans ${ }^{10} \mathrm{e}$ Pseudomonas putida ${ }^{34}$ em meios apropriados, como material de reserva de energia e têm como principais vantagens sua biocompatibilidade e biodegradabilidade ${ }^{35}$. Koizimi et al. $^{32}$ empregaram células de Alcaligens eutrophus, que crescem sob condições aeróbias à $30^{\circ} \mathrm{C}$, por $24 \mathrm{~h}$ em um meio rico de extrato de levedura, de carne e polipeptona. Diferentes quantidades de frutose e ácido butírico foram adicionadas ao meio como fonte de carbono. O material foi

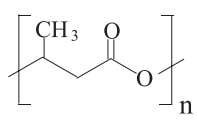

(a)

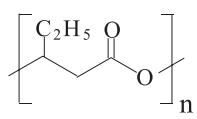

(b)

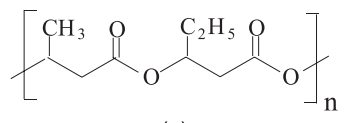

(c)
Figura 4. Estrutura química dos poli(hidroxialcanoatos) (PHAs): a) poli( ${ }^{2-}$ hidroxibutirato); b) poli(2-hidroxivalerato) e, c) poli( ${ }^{2}$-hidroxibutirato-covalerato)

centrifugado, o sobrenadante foi retirado e as células lavadas com água destilada e liofilizadas. O polímero biodegradável, PHB, foi extraído com clorofórmio, sob agitação, durante 48 h e o material filtrado ${ }^{32}$.

PHB é um polímero cristalino com alta temperatura de fusão $\left(\mathrm{T}_{\mathrm{f}}=180{ }^{\circ} \mathrm{C}\right)$ e temperatura de transição vítrea $\left(\mathrm{T}_{\mathrm{g}}\right)$ de cerca de $5{ }^{\circ} \mathrm{C}$. Isto torna os filmes de PHB muito quebradiços, o que pode ser melhorado utilizando-se o copolímero PHB-V (Biopol). Este copolímero foi sintetizado pela primeira vez pela ICI (UK) em 1983 e, em 1990, garrafas deste material foram produzidas na Alemanha, para embalar shampoo ${ }^{10}$. O preço corrente do Biopol na Inglaterra é de $£ 8000 / t$, comparado com $£ 500 /$ t de outros polímeros comuns como poli(cloreto de vinila) (PVC) e polipropileno (PP) e $£ 600 / t$ para polietileno de alta densidade (PEAD) e poliestireno $(\mathrm{PS})^{10}$. Poliésteres microbianos são relativamente resistentes à hidrólise química, mas são suscetíveis ao ataque bacteriológico, o que restringe seu uso para embalar alimentos. Entretanto, o PHB$\mathrm{V}$ tem excelentes propriedades de barreira à gás e pode ser usado associado com camadas de gelatinas metacriladas, que conferem ao produto uma baixa permeabilidade ao oxigênio, alta resistência à água em ebulição e boa capacidade de adesão ${ }^{10}$.

\section{POLÍMEROS BIODEGRADÁVEIS SINTÉTICOS}

Esta classe de polímeros tem sido muito empregada em usos biomédicos, tais como cápsulas de liberação controlada de droga em organismos vivos, fixadores em cirurgias (suturas, clips, pinos para ossos) e para embalagens especiais. Os polímeros mais usados têm sido poli(ácido lático) (PLA), poli(ácido glicólico) (PGA), poli(ácido glicólico-ácido lático) (PGLA), poli(ع-caprolactona) (PCL) (Figura 5) ${ }^{10,21}$. Estes polímeros são ésteres alifáticos biodegradáveis, por possuírem cadeias carbônicas hidrolizáveis. Se a biodegradação for por meio da ação de enzimas, a cadeia polimérica deve se ajustar aos sítios ativos das enzimas e isto é favorecido pela flexibilidade das cadeias poliméricas alifáticas, o que não ocorre com os poliésteres aromáticos. PLA, PGA e PGLA são poliéste-<smiles>CC(C)(C)CCCCCOC(C)(C)C</smiles>

(a)

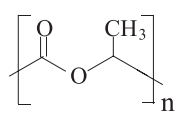

(b)

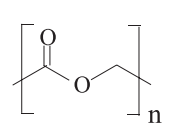

(c)

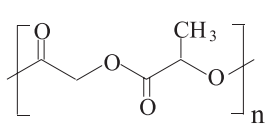

(d)
Figura 5. Estrutura química de: a) poli(e-caprolactona) $(P C L)$; b) poli(ácido lático) (PLA); c) poli(ácido glicólico) (PGA) e, d) poli(ácido glicólico-lático) (PGLA) 
res muito utilizados em suturas absorvíveis dentro de um sistema vivo, sendo que uma grande vantagem é sua biodegradabilidade por hidrólise simples da cadeia de éster em meio aquoso, ou seja, nos fluidos corporais ${ }^{21}$. PCL foi muito estudado como substrato para biodegradação e como matriz para liberação controlada de drogas. PCL é biodegradado através da hidrólise enzimática, por fungos $^{21}$. Suas constantes físicas, temperatura de transição vítrea$\mathrm{T}_{\sigma}$ e temperatura de fusão- $\mathrm{T}_{\mathrm{f}}$ são para o PCL -60 e $60{ }^{\circ} \mathrm{C}$, para o PLA 58 e $180^{\circ} \mathrm{C}$ e para o PGA 36 e $224-226^{\circ} \mathrm{C}$, respectivamente ${ }^{10}$.

\section{BIODEGRADAÇÃO/BIODETERIORAÇÃO}

Estudos de biodegradação, in vivo e in vitro, são importantes, tanto para minimizar os efeitos de resíduos plásticos sintéticos descartados no meio ambiente, como para aplicar mais os polímeros biodegradáveis às áreas médica e de embalagens ${ }^{36}$.

A biodegradação de polímeros ocorre, basicamente, por dois mecanismos distintos dependendo da natureza do polímero e do meio $^{37}$ : hidrólise biológica e oxidação biológica

\section{Hidrólise biológica}

É a hidrólise catalisada por enzimas hidrolases. Certas enzimas proteolíticas (proteases) catalisam a hidrólise de ligações peptídicas e outras catalisam a hidrólise de ligações éster ${ }^{21}$. Este mecanismo é seguido pela oxidação biológica das cadeias poliméricas (catalisada pelas oxigenases), quebra das mesmas, gerando cadeias menores e bioassimilação destas pelos microrganismos. Este processo ocorre em polímeros contendo hetero-cadeias, tais como celulose, amido e poliésteres alifáticos, dos quais os PHAs são típi$\cos ^{37}$. Os grupos ésteres deste polímeros são facilmente hidrolisáveis, pela ação enzimática das esterases de fungos ${ }^{21}$.

\section{Oxidação biológica}

É a reação de oxidação, na presença de oxigênio, com introdução de grupos peróxidos nas cadeias carbônicas, por ação das monooxigenases e dioxigenases, quebra das cadeias, seguida por bioassimilação de produtos de baixa massa molar, como ácidos carboxílicos, aldeídos, cetonas. Este mecanismo se aplica essencialmente a polímeros apenas de cadeias carbônicas. A degradação pode ser controlada pelo uso apropriado de antioxidantes. A bioassimilação começa tão logo forem formados produtos de baixa massa molar no processo de peroxidação ${ }^{21,37}$.

Em geral, a velocidade de hidrólise dos polímeros é controlada por várias propriedades, incluindo estrutura, área superficial e morfologia. A susceptibilidade de polímeros à degradação enzimática é determinada pela relação entre propriedades e estrutura. Os microrganismos secretam enzimas que quebram o polímero em blocos moleculares menores, hidroxiácidos, que são utilizados como fonte de carbono para o crescimento destes microrganismos. Neste sentido é conhecido, por ex., o desempenho das enzimas despolimerases de Penicillium funiculosum e Aspergillus fumigatus na biodegradação de poliésteres bacterianos. A incubação de filmes de PHB e PHB-V em lodos anaeróbios mostrou significativa degradação em um tempo de 6 a 10 semanas, a $37{ }^{\circ} \mathrm{C}$, monitorada por perda de massa dos filmes e formação de biogás ${ }^{38}$. PHB foi degradado anaerobicamente ( $23 \%$ de perda de massa), mais rapidamente que o copoliéster PHB-V (22,5\% de perda de massa). PCL degradou mais lentamente e menos $(7,6 \%$ de perda de massa) que os poliésteres naturais $\mathrm{PHB}$ e $\mathrm{PHB}-\mathrm{V}^{38}$. Outro estudo revelou que lipase de Pseudomonas é capaz de acelerar a biodegradação do PCL e esta ocorre principalmente na superfície da matriz, pois é difícil para uma enzima hidrofílica difundir para o interior do polímero hidrofóbico ${ }^{36}$. Outro trabalho investigou a biodegradação de PHB e "Sky-Green (SG)", um polímero biodegradável de ácido succínico, ácido adípico e etileno glicol e "Mater-Bi (MB)", um compósito de polímero biodegradável e amido, incubados em solo de floresta, em areia e em lodo ativado, a 28,37 e $60{ }^{\circ} \mathrm{C}^{39}$. Neste estudo verificou-se que a degradação dos três materiais era mais ativa em lodo ativado e que $\mathrm{SG}$ e $\mathrm{MB}$ eram mais degradáveis a 28 que a $37{ }^{\circ} \mathrm{C}$, enquanto que PHB degradava mais à $37^{\circ} \mathrm{C}^{39}$. Outros estudos mostraram que $85 \%$ de poli(hidroxialcanoatos) (PHA) degradaram em 7 semanas $^{40,41}$. PHA em meio aquático (lago Lugano, Suíça), degradou em 254 dias, a temperaturas abaixo de $6{ }^{\circ} \mathrm{C}^{40}$. Filmes de PCL e PHB de $50 \mu \mathrm{m}$ submetidos a biotratamento em água do mar, durante 10 semanas, mostraram mudanças morfológicas importantes e perda de massa de 25 e 9\%, respectivamente, porém o PLA, utilizado no experimento, não mostrou mudanças significativas, relacionadas à morfologia e à massa ${ }^{42}$.

A biodegradação sob ação de enzimas pode ser monitorada por medidas de massa molar (Cromatografia de Permeação em GelGPC), da presença de grupos polares (Infravermelho com Transformada de Fourier - FTIR), de mudanças nas propriedades mecânicas (Análise Termo-Mecano-Dinâmica - DMTA), de mudanças de estrutura de microfase (Calorimetria Exploratória Diferencial DSC) ou de estrutura de macrofase (Microscopia Eletrônica de Varredura - SEM $)^{43}$. A biodegradação envolve não só a ação de enzimas como também outros mecanismos de interação entre os microrganismos e a superfície polimérica e pode ser chamada de biodeterioração ${ }^{16}$.

A biodeterioração é um processo interfacial, em que os microrganismos atacam e colonizam as superfícies poliméricas na forma de biofilmes, os quais são uma mistura de microrganismos, água, polissacarídeos e proteínas que, em contato com o polímero sintético, causam algumas modificações, entre elas ${ }^{16}$ : cobertura da superfície, mascarando suas propriedades superficiais e contaminando o meio adjacente; aumento da dessorção de aditivos e monômeros para fora da matriz; ataque ao polímero por enzimas; acúmulo de água e penetração na matriz com filamentos microbianos, causando entumescimento e aumento de condutividade e, excreção de pigmentos microbianos lipofílicos que colorem o polímero.

A biodeterioração é então um processo muito complexo, que depende das condições do meio, dos tipos de microrganismos e da estrutura do polímero propriamente dito. Se o polímero for biodegradável, isto é, com estrutura de cadeias alifáticas e grupos funcionais hidrolisáveis, o processo pode ocorrer, sob certas condições do meio ( $\mathrm{pH}$, umidade, oxigênio, etc), de maneira mais direta por ação de enzimas: hidrólise e subseqüente oxidação ${ }^{10}$. Se o polímero não tiver grupos funcionais, como os ésteres, pode haver deterioração, mas não chegando a mineralização do polímero até os produtos finais: água e dióxido de carbono ou metano. A superfície polimérica pode ser inerte ao ataque microbiano, sendo apenas um suporte para o crescimento bacteriano ${ }^{16}$.

Os microrganismos podem agir de diferentes maneiras sobre a superfície polimérica: por deposição de material extracelular excretado por eles ("fouling"); por degradação de compostos extraídos (lixiviados) do polímero, tais como, aditivos e monômeros, os quais servem de alimento e manutenção para o biofilme - como ex., podemos citar as cortinas de PVC, usadas em boxes de banheiros, que perdem a flexibilidade, pela perda de aditivos; por corrosão - isto é, pela ação do biofilme e de seu gradiente de $\mathrm{pH}$ e potencial de óxido-redução, que ajudam na deterioração do polímero. Corrosão deste tipo ocorreu em isolantes elétricos, poliuretanas, usados em vários equipamentos do aeroporto de $\mathrm{Zu}$ rique, entre 1967 e 1969, que foram completamente deteriorados 
pela colonização e penetração de fungos nos equipamentos ${ }^{16}$, por hidratação e penetração, devido à composição do biofilme $(95 \%$ de água), ele se constitui em um eletrólito e aumenta a condutividade na superfície do polímero e isto leva a falhas no funcionamento de equipamentos elétricos, por ex., crescimento de fungos em circuitos impressos, o que pode afetar a condutividade e causar curtocircuitos. As hifas de fungos podem penetrar no material polimérico e provocar diminuição de sua estabilidade mecânica; podem colorir o filme polimérico - isto é, o biofilme pode conter microrganismos que produzem pigmentos lipofílicos que difundem na superfície da matriz polimérica ${ }^{16}$.

Para quantificar a biodegradação/biodeterioração tem sido empregados vários métodos físico-quimícos, que ainda não estão totalmente padronizados pois, em se tratando de interações entre microrganismos e superfícies poliméricas, que são processos complexos, é difícil a padronização dos métodos.

\section{ALGUNS MÉTODOS PARA SE ESTUDAR A BIODEGRADAÇÃO/BIODETERIORAÇÃO DE POLÍMEROS}

\section{Plaqueamento em ágar}

Consiste na inoculação de espécies de microrganismos, na presença do polímero, sob condições favoráveis de crescimento. Remoção das espécies e testes para verificação de mudanças nas propriedades físicas ou químicas do material polimérico, isto é, após remover os microrganismos efetuam-se medidas de ensaios mecânicos, absorção na região do infravermelho e do UV-Visível e análise de Massa Molar para verificar as possíveis alterações ocorridas no polímero ${ }^{44}$.

\section{Marcação com ${ }^{14} \mathrm{C}$}

Distingue $\mathrm{O}_{2}$ produzido no metabolismo do polímero do $\mathrm{CO}_{2}$ gerado por outras fontes de carbono, como as do solo (se o polímero estiver em coluna de solo) ou as do meio de cultura (se o polímero estiver incubado em meio de cultura e microrganismos) ${ }^{44}$.

\section{Enriquecimento do solo}

Para isolar espécies que crescem sobre o polímero, isto é, incubar o filme polimérico em solo, durante um certo tempo, depois separar os microrganismos que se desenvolveram na presença do filme. Incubá-los em meio apropriado e com o filme, durante um tempo, retirar o filme e analisar suas propriedades mecânicas e físico-químicas ${ }^{44}$.

\section{Teste in vitro}

Envolve dois métodos biológicos quantitativos: a respirometria, em que a atividade do microrganismo é medida por meio da absorção de $\mathrm{O}_{2}$ ou liberação de $\mathrm{CO}_{2}$, captado sobre $\mathrm{KOH}$ ou sobre $\mathrm{Ba}(\mathrm{OH})_{2}$ (método de Sturm) ${ }^{31}$. E a perda de massa da amostra, em que se mede a massa do polímero antes e após o tratamento microbiano ${ }^{44,45}$.

Além das medidas de ensaios mecânicos para se testar o polímero tratado microbiologicamente, empregam-se ainda medidas do conteúdo de plastificante de certos polímeros após o tratamento microbiano, para avaliar as mudanças nas propriedades do polímero ${ }^{46}$.

$\mathrm{Na}$ avaliação da biodegradabilidade de plásticos, também se utiliza o teste de zona clara em meio ágar sólido ${ }^{47}$. O meio sólido contém partículas de polímeros suspensos ou um pedaço do filme polimérico e o inóculo de uma espécie de bactéria ou fungo, sobre o polímero. A formação de uma zona clara, distinta, de área circular, indica a degradação do polímero em moléculas menores e solúveis ao redor da colônia. Este processo depende da excreção de enzimas extracelulares, da sua difusão através do meio e da interação entre enzimas e polímero ${ }^{47}$. Esta interação não só está relacionada a fenômenos superficiais, tais como a adesão, bem como à conversão química propriamente dita ${ }^{47}$. A adesão da bactéria a superfícies (PVC, TEFLON) torna-se um fator de proteção da bactéria ligada, que contrabalança o efeito esperado pela ação de certos bactericidas $^{48}$. A interação de microrganismos com materiais de embalagens de PVC deve-se à sua hidrofobicidade, atividade lipolítica e capacidade de adesão, o que pode ser a causa do mau cheiro de certas garrafas de água mineral ${ }^{49}$.

Uma vez que a interação entre microrganismos e polímeros se inicia pela superfície, são empregadas técnicas específicas e usuais para investigar alterações na superfície polimérica, dentre elas destacam-se a espectroscopia fotoeletrônica de raios-X (XPS), a microscopia eletrônica de varredura (MEV), o ângulo de contato e a espectroscopia no infravermelho com transformada de Fourier (FTIR) e com refletância atenuada ${ }^{50}$.

\section{CONCLUSÃO}

O emprego de polímeros biodegradáveis naturais (PHB, PHB-V) ou sintéticos (PCL, PLA, PGA) no mercado ainda não é significativo, mas deverá ser mais expressivo em futuro próximo, uma vez que estes polímeros geram resíduos de curta duração, em relação aos plásticos sintéticos (PET, PE, PP, PVC) e tem crescido a pesquisa a respeito da aplicação tecnológica e da duração de seus resíduos. Os polímeros biodegradáveis sofrem mais facilmente a ação de microrganismos, por conterem funções orgânicas em suas cadeias alifáticas: carbonilas, hidroxilas, ésteres, hidroxiácidos, mais suscetíveis à ação enzimática, entretanto, é importante lembrar que esta ação depende de fatores, tais como tipos de microrganismos presentes, condições do meio (temperatura, umidade, $\mathrm{pH}$, luz, $\mathrm{O}_{2}$ ) e propriedades do polímero (massa molar, cristalinidade, etc).

\section{REFERÊNCIAS}

1. Huang, S. J.; J. Mat. Sci. - Pure Appl. Chem. 1995, A 32, 493.

2. Reddy, C. S. K.; Ghai, R; Rashimi; Kalia, V. C.; Bioresour. Technol. 2003, 87, 137.

3. Huang, S. J.; Edelman, P. G.; Degradable Polymers: Principles and Applications, Scott, G.; Gilead, D., eds.; Chapman \& Hall: London, 1995.

4. Agnelli, J. A. M.; Polímeros: Ciência e Tecnologia 1996, 4, 9.

5. Leão, A. L.; Tan, L. H.; Biomass and Bioenergy 1998, 14, 83.

6. Kirbas, Z.; Environ. Contamin. Toxicol. 1999, 63, 335.

7. Torikai , A.; Hasegawa, H.; Polym. Degrad. Stab. 1999, 63, 441.

8. Shrivram, D.; International Symposium on Biodegradation Polymers, Hyderabad, Índia, 2001

9. Kalia, V. C.; Raizada, N.; Sonakya, V.; Bioplastics J. Sci. Ind. Res. 2000, $59,433$.

10. Amass, W.; Amass, A.; Tighe, B.; Polym. Int. 1998, 47, 89.

11. Lee, S. Y.; Choi, J.; Polym. Degrad. Stab. 1998, 59, 387.

12. Rosa, D. S.; Lotto, N. T.; Guedes, C. G. F.; Polym. Test. 2004, 23, 3

13. Karlsson, S.; Albertsson, A. C.; Polym. Eng. Sci. 1998, 38, 1251.

14. Varma, A. J.; Polym. Degrad. Stab.1999, 63, 1.

15. Spinacé, M. A. S.; De Paoli, M. A. ; Quim. Nova 2005, 28, 65.

16. Flemming, H. C.; Polym. Degrad, Stab. 1998, 59, 309.

17. Xu, X.; Guo, S. A.; Polym. Plast. Technol. Eng. 1995, 34, 621.

18. Paci, M; La Mantia, F. P.; Polym. Degrad. Stab. 1999, 63, 11.

19. Raghavan, D.; Polym. Plast. Technol. Eng. 1995, 42, 41.

20. Korner, I.; Redemann, K.; Stegmann, R.; Waste Manag. 2005, 25, 409.

21. Chandra, R.; Rustgi, R.; Prog. Polym. Sci. 1998, 23, 1273.

22. Lee, S. Y.; Choi, J.; Polim. Degrad. Stab. 1998, 59, 387.

23. Nonato, R. V.; Mantelatto, P. E.; Rossell, C. E. V.; Appl. Microbiol. Biotechnol. 2001, 57, 1. 
24. Bertrand, J. L.; PhD Thesis, Université de Montreal, Canadá, 1992.

25. Gomes, J. G. C.; Bueno Netto, C. L.; Rev. Bras. Eng. Quim. 1997, 17, 24.

26. Vendruscolo, C. W.; Andreazza, I. F.; Ganter, J. L. M. S.; Ferrero, C.; Bresolin, T. M. B.; Int. J. Pharm. 2005, 296, 1

27. Santos, H.; Veiga, F.; Pina, M. E.; Souza, J. J.; Int. J. Pharm. 2005, 295, 15.

28. Khanna, S.; Srivastava, A. K.; Process Biochem. 2005, 40, 607.

29. Arvanitoyannis, I.; Biliaderis, C. G.; Ogawa, H.; Kawasaki, N.; Carbohydr. Polym. 1998, 36, 89.

30. Tudorachi, N.; Cascaval, C. N.; Rusu, N.; Pruteanu, M.; Polym. Test. 2000, 19,785

31. Lehninger, A. L.; Nelson, D. L.; Cox, M. M.; Principles of Biochemistry, $2^{\text {nd }}$ ed., Worth Publisher, Inc.: New York, 1993.

32. Koizumi, F.; Abe, H.; Doi, Y.; J. Mat. Sci.- Pure Appl. Chem. 1995, A 32, 759.

33. Du, G. C.; Chen, J.; Yu, J.; Lun, S.; Biochem. Eng. J. 2001, 8, 103.

34. Koning, G.; Witholt, B.; Mater. Sci Eng., C 1996, 4, 121.

35. Gracida, J.; Alba, J.; Cardoso, J.; Perez-Guevara, F.; Polym. Degrad. Stab. 2004, 83, 247.

36. Wu, C.; Gan, Z.; Polymer 1998, 18, 4429.

37. Scott, G.; Polym. Degrad. Stab. 2000, 68, 1.

38. Abou-Zeid, D.-M.; Muller, R.-J.; Deckwer, W.-D.; J. Biotechnol. 2001, 86, 113.
39. Kim, M-N.; Lee, A.-R.; Yoon, J-S.; Chin, I-J.; Eur. Polym. J. 2000, 36, 1677.

40. Johnstone, B.; Far Eastearn Econ. Rev. 1990, 147, 62.

41. Fletcher, A.; Plastics from bacteria: PHA as Natural, Biodegradable Polyesters, Springer Verlag: New York, 1993.

42. Tsuji, H.; Suzuyoshi, K.; Polym. Degrad. Stab. 2002, 75, 347.

43. Zuchowska, D.; Hlavatá, D.; Steller, R.; Adamiak, W.; Meissner, W.; Polym. Degrad. Stab. 1999, 64, 339.

44. Kumar, S. G.; Kalpagam, V.; Nandi, U. S.; J. Mat. Sci.- Review Macromol. Chem. Phys. 1992, C22, 255.

45. Rosa, D. S.; Pântano-Filho, R.; Biodegradação - um ensaio com polímeros, Ed. Moara: São Paulo, 2003.

46. Yabanavar, A. V.; Bartha, R.; Appl. Environ. Microbiol. 1994, 60, 3608

47. Augusta, J.; Muller, R. J.; Widdecke, H. A.; Appl. Microbiol. Biotechnol. 1993, 39, 673

48. Vess, R. W.; Anderson, R. L.; Carr, J. H.; Bond, W. W.; Favero, M. S. J.; Appl. Bact. 1993, 215.

49. Guerzoni, M. E.; Lanciotti, R.; Singaglia, I.; Microbiol. Res. 1994, 149, 115.

50. Ratner, B. D.; Llach-Scampava,l D.; Castner, D. G.; Biomaterials 1993 $14,148$. 